\title{
Introducing University Pitch Competitions: An Analysis of the First Five Years
}

\author{
David P. Price \\ Washburn University
}

This paper centers on the introduction and development of a business pitch competition in a medium-sized Midwest university in the United States, held from 2014-2018. First, the study analyses the evolution and development of our competition over the first five years of its implementation, detailing successes, missteps and pivot points during this time. Second, it presents a comparative study of other university competitions of varying sizes across the United States, highlighting the wide range of pitch programming design used by other institutions. Third, interviews were conducted with stakeholders from past competitions to understand further potential areas for improvement, which included student participants, community business leaders that participated as judges, and partner and university administrators. This process immediately improved the competition, and the advantages and disadvantages of the event are discussed. Lastly, a road map or best practice template is provided for other institutions to help implement their own version of a pitch competition. This template can serve as a foundation for other universities and/or organizations to implement a successful competition in a shorter timeframe.

Keywords: pitch competitions, university entrepreneurship programs, interviews, best practices

\section{INTRODUCTION AND PITCH COMPETITIONS}

In 1985, there were about 250 courses offered in entrepreneurship at college campuses across the United States, by 2008, that number had increased to 5,000 (Ewing Marion Kauffman Foundation). This illustrates the importance of entrepreneurship programs to universities in the United States and internationally, and the battle between institutions for new and engaging programs to grow student enrollment. However, while there remains debate on how to teach entrepreneurship and what the curriculum should be (Morris, Kuratko \& Pryor, 2014), the art of pitching or effectively communicating a business idea to potential investors or other stakeholders, has long been deemed critical by entrepreneurship faculty and indeed general business scholars (Balachandra \& Fischer, 2016).

Commonly referred to as an 'Elevator Pitch,' the term references the brevity associated with elevator rides and has come to represent the familiar concept and skill that would-be entrepreneurs must master to successfully advance a business idea (Cremades, 2016; Katz \& Green, 2009). Universities have institutionalized the elevator pitch making it synonymous with entrepreneurship education. The number of U.S. institutions that hold pitch competitions is in the hundreds, and many high schools, private and public sector organizations host pitching events each year (Clingingsmith \& Shane, 2018). Pitching a business idea is viewed as a pathway to financing, partnerships and other resource advantages (Clark, 2008). 
Literature on pitching has received much attention from practitioners and investors (for example McGowen, 2015); but academic literature suggests a sparsity of evidence for key concepts of the pitch or the best way to teach it (Clingingsmith \& Shane, 2018; Maxwell \& Lévesque, 2014). However it is viewed, most practitioners and academics alike agree that practice through pitch training helps entrepreneurs and aspiring students communicate their business ideas more clearly and with greater precision. Thus, pitch competitions are helpful to would-be entrepreneurs and in this case any student that wants to more effectively "sell" a product, service or idea to any prospective client or stakeholder. Therefore, the question remains about the best way to incorporate this training in a university environment, in a way that benefits not only the students but also the business community and institution.

This paper outlines the successful introduction of a pitch competition at a medium-sized, midwestern university in the United States. It examines the historical evolution of the event over the first five years, its successes and pitfalls, and attempts to gain additional insight for the future based on comparisons with other schools and interviews from participants, judges, and administrators. A best practice and guide for implementation is provided that can serve as a foundation for other institutions that are considering the addition of a pitch competition.

\section{EVOLUTION OF OUR OWN PITCH COMPETITION}

\section{Year 1 - Introduction and Development \\ Introduction of the Competition}

In the aftermath of the 2008/2009 "great recession" the university like many around the United States were feeling economic woes from declining student enrollment and major reductions in state funding. A committee had already formed to discuss the merits of introducing an entrepreneurship program that included a new major in the area, and the economic hardships accelerated the momentum of the project. From 2010-2013 a committee developed and introduced an "Entrepreneurship \& Innovation" major, the first new major at this university in 30 years which was a significant achievement itself.

The emergence of the major was met with enthusiasm from many business school alumni, as many had gone on and created their own firms and wanted to participate by contributing both financial support and expertise. The launch of the program was announced for the fall of 2014, and while a pitch competition was part of the proposal, we had planned on introducing it the following year after getting some traction with the major. However, we were approached by a local economic development group with a mandate to increase entrepreneurship activity in the local area (due in large part to the recession), and entrepreneurs were viewed as a resource to create new jobs and business activity. Importantly, this group had a recent tax fund to draw on and were interested in our new program as a way to develop the next generation of entrepreneurs. They offered $\$ 12,000$ prizemoney for the first year and our university handled the operations of the entire competition.

\section{Development of the Competition}

Our early objectives were to organize the event in a way that could help us generate excitement for the event, our new program, promote entrepreneurship across the campus and in the business community. With these goals in mind, the decision was made to offer the competition to any student at the university, no matter their discipline, whether full-time or part-time, undergraduate or graduate to increase the pool of potential candidates. At the time, our focus was to develop student ideas that could begin their business ideas immediately, and would begin to take steps to organize and begin operations. To that extent, prizemoney was organized to award the top four finishers with a smaller prizemoney amount, and then make the bulk of the remaining funds available as reimbursable expenses to ensure they begin their business. A "How to Pitch" handout was developed and posted on the School website, along with the judging criteria and how the event would be managed. Lastly, a free seminar was offered to any student wanting more information on how to pitch hosted by the Director of the Small Business Development Center. 
The event was designed as a two-tiered system, with the first tier to sift through the multitude of entries to find the best proposals. The first tier or "Knockout Round" (KR) assigned all entries into four separate pools/rooms over two hours during the afternoon, usually $1-3 \mathrm{pm}$. The decision was made to exclude faculty from judging as they were often helping students develop their pitch. Therefore, each pool/room had three separate judges from the local business community who were volunteering their time to participate. Each room had a list of entries so every student knew the order they would pitch and were asked to in the room when their name was called. Chairs were provided and guests could listen and other competitors could hear other student pitches before and after their own.

Students had a maximum of three minutes to pitch and were not allowed to use any technology (PPT, phones, etc.) although other material could be used such as prototypes, handouts, promotional materials, etc. Each room had 11-12 pitches and judges were asked to keep questions to a minimum and only ask questions if further clarification was needed in order to keep on time. Judges were provided with scoresheets which were kept deliberately simple due to the fast-paced atmosphere and had four categories: Innovation, Business Model, Feasibility and Presentation (the Judging Criteria used in the KR is included in the appendix). A timekeeper/organizer was provided in each room who kept time and called for participants, and after the pitches were completed the judges would tally their scores together and deliver the winning entry to the organizer. The top entry from each of the rooms would progress to the "Finals Round" (FR) that would take place approximately two weeks later.

The Finals Round was designed to be a celebration event, including a sit-down dinner, a local celebrity MC (local news broadcaster), family, friends, alumni, faculty, staff and other important stakeholders. Students in this tier had to expand on their pitch idea, having a total of seven minutes to discuss their opportunity and use technology such as PowerPoint in their presentations. Five different judges were asked to participate and were encouraged to ask questions and interact with the students (the judging criteria used in both the KR and FR can be seen in the appendix), but both sets of criteria are intended to be similar to make the transition for students into the extra detail required for their FR business pitch more accommodating. The Finals Round design has proven to be popular, especially as it gives an opportunity for sponsors to see the how their prizemoney had encouraged entrepreneurship and allowed for exposure through a multitude of public relations channels.

The event was promoted using posters on campus, emails to students, talking in person to various classes (not just entrepreneurship), and asking entrepreneurship faculty to include the pitch competition as part of the assessment for that semester. The event attracted a total of 85 students with 46 entries (students could enter as a team of up to three students).

\section{Year 2 - Tweaks and Adjustments}

The success of the first edition of the competition led the sponsors to commit to the following year, however they had some concerns that had to be addressed. Most important was the allocation of prizemoney, specifically the reimbursable expenses. The sponsor wanted to decide on the legitimacy of the business expenses to ensure students were actually starting a business, however this quickly became an issue as students made dubious claims that normally do not qualify as expenses in a normal business environment. This led to a sizeable portion of the prizemoney not being claimed, and a raft of administrative work on the sponsors part in deciphering claims and processing paperwork. Therefore, in Year 2 we decided to dramatically reduce the reimbursable expenses and offer more prizemoney (see Table 1). Additionally, due to the closeness in quality of some of the pitches, we added a fifth place for the Finals Round, which was decided by the closest second-place finisher in any room (or smallest margin between first and second).

The success experienced in Year 1 led us to maintain the format and with a prizemoney shift, we increased our marketing efforts. This included more visits to classes, extra emails plus exposure through articles in the school newspaper. Positive word-of-mouth amongst the student population (particularly in the business school), was achieved and this led to an increase in entries to 120 students or 73 total entries. However, while this appeared initially as good news, it led to operational challenges, for example going over time during the Knockout Round and simply overwhelming staff and faculty resources. Additionally, 
the quality of many pitches was down, and it appeared the push for entries had reached a point of diminishing returns.

\section{Year 3 - Big Changes for the Better}

The continued success of the event was measured in a number of ways, firstly the number of students participating was exciting, and we were attracting students from other disciplines to achieve our crossdiscipline goal. Local news coverage of the event had a positive effect with our sponsor and administrators were happy as we were experiencing increasing enrollment in the entrepreneurship major. This led to a surprising development during the third year where our sponsor decided to double the prizemoney to $\$ 25,000$. Other changes included the total elimination of reimbursable expenses, making the awards even more attractive to students. The increase in prizemoney and the success of our cross-discipline efforts drove a new category for an award called the "Top Tech Entry" which was developed through a collaboration with a local technical school, and prizemoney was offered for the top entry from that school alone. Additionally, we wanted to encourage first-time students and developed the "Top Freshman Award." These new categories spurred interest from a new crop of students and offered additional diversity as it is normally dominated by junior and senior business students.

With the new categories and anticipated entries, we decided to reduce the number of finalists to four. We were also more prepared for the number of students and allocated more time during the Knockout Round. Numbers were strong, with 111 total students participating with 70 total entries.

\section{Year 4 - Refining the Competition for Better Results}

Despite the success of the event to date, we still had not created many student ventures that went on to start a business, and this was a part of the discussion that summer as to how we could achieve this. We made a strategic decision to focus less on the number of entries and more on quality, and reduced the amount of marketing and having the event as a "requirement" for some classes. Instead, we focused on encouraging those students that showed a desire for entrepreneurship and to encourage faculty to help these individuals. In 2017 we had 64 total students and 51 entries, and while numbers were down it was anticipated and made the KR far more manageable. Importantly our sponsor was pleased with the quality of the results, and this remained a focus for future events.

\section{Year 5 - Developing the Bigger Picture}

Our experience with the event by 2018 was one of achieving balance, a balance between generating enthusiasm across campus about entrepreneurship and introducing new students to the event and our programs, but also with training students to effectively pitch and hopefully start a new venture. While still maintaining our basic format of the two-tiered system, we included a new category to pay for our winner to participate in the national pitch competition hosted by the Collegiate Entrepreneurs Organization (CEO). We hoped this would give our students additional exposure to entrepreneurship on a national scale, not only with pitching but with many other elements of new venture development. By competing against the best in the United States (and internationally), it raises the expectations of quality. The students in the university entrepreneurship club were also encouraged to participate in the annual conference. Additionally, the CEO at that time would waive the entry fee for any university that hosts their own pitch competition. There were 67 students entered this year with 45 entries.

TABLE 1

PRIZEMONEY, CATEGORIES AND NUMBER OF STUDENTS (2014-2018)

\begin{tabular}{|l|l|l|l|l|l|}
\hline & $\mathbf{2 0 1 4}$ & $\mathbf{2 0 1 5}$ & $\mathbf{2 0 1 6}$ & $\mathbf{2 0 1 7}$ & $\mathbf{2 0 1 8}$ \\
\hline Total Prizemoney & $\$ 12,000$ & $\$ 12,000$ & $\$ 25,000$ & $\$ 25,000$ & $\$ 25,000$ \\
\hline 1st & $\$ 1,000$ & $\$ 4,000$ & $\$ 9,000$ & $\$ 8,000$ & $\$ 8,000$ \\
\hline 2nd & $\$ 750$ & $\$ 3,000$ & $\$ 6,000$ & $\$ 6,000$ & $\$ 6,000$ \\
\hline
\end{tabular}




\begin{tabular}{|l|l|l|l|l|l|}
\hline 3rd & $\$ 500$ & $\$ 500$ & $\$ 4,000$ & $\$ 4,000$ & $\$ 4,000$ \\
\hline 4th & $\$ 250$ & $\$ 250$ & $\$ 2,500$ & $\$ 2,000$ & $\$ 2,000$ \\
\hline 5th & & $\$ 250$ & & $\$ 1,000$ & $\$ 1,000$ \\
\hline Other - Top Tech Entry & & & $\$ 2,500$ & $\$ 2,500$ & $\$ 2,500$ \\
\hline Other - Top Freshman Award & & & $\$ 1,000$ & $\$ 1,000$ & $\$ 1,000$ \\
\hline Other - Conference Support & & & & & $\$ 500$ \\
\hline Other - Reimbursable Expenses & $\$ 9,500$ & $\$ 4,000$ & & & \\
\hline Student \#s & & & & & \\
\hline Total Students & 85 & 120 & 111 & 64 & 67 \\
\hline Total Entries & 46 & 73 & 70 & 51 & 45 \\
\hline
\end{tabular}

\section{COMPARISONS WITH OTHER COMPETITIONS}

The competition developed for our university was based on research of other pitch events offered at the time, and unique additions were made that best suited our needs and resources. However, it is beneficial to compare our event with other schools to generate new viewpoints and understanding. Below is a table that presents pitch competitions from a variety of universities from around the United States. While this is by no means exhaustive, it does allow for some comparisons between events and insights into differences and possible new design. The information was derived based firstly on a mix of school size based on student population (large, medium and small) and the amount of publicly available information listed on their website.

TABLE 2

UNIVERSITY PITCH COMPETITION COMPARISONS (U.S.)

\begin{tabular}{|c|c|c|c|c|c|}
\hline $\begin{array}{l}\text { School } \\
\text { Size }\end{array}$ & Date Held & $\begin{array}{l}\text { Pitch } \\
\text { Length }\end{array}$ & $\begin{array}{l}\text { Rounds \& } \\
\text { Req. }\end{array}$ & Prizemoney & Other \\
\hline Large & Spring/April & $2 \mathrm{mins}$ & One round & $\begin{array}{l}1 \mathrm{st}=\$ 1000 ; \\
2 \mathrm{nd}=\$ 500 ; 3 \mathrm{rd}=\$ 250 \\
+ \text { Addl. Awards }= \\
\$ 250, \text { t-shirts }\end{array}$ & $\begin{array}{l}2 \text { Divisions; one } \\
\text { student must be } \\
\text { enrolled in Ent. } \\
\text { Program }\end{array}$ \\
\hline Small & Spring/April & $2 \mathrm{mins}$ & One Round & $\begin{array}{l}1 \mathrm{st}+\$ 500 ; \\
2 \mathrm{nd}=\$ 250 ; \\
3 \mathrm{rd}=\$ 150 ; 4 \mathrm{th}=\$ 100\end{array}$ & $\begin{array}{l}\text { Combined with } \\
\text { other schools \& } \\
\text { comps }\end{array}$ \\
\hline Medium & Fall/Nov & $2 \mathrm{mins}$ & One Round & $\begin{array}{l}1 \mathrm{st}=\$ 2500 \\
2 \mathrm{nd}=\$ 1500 \\
3 \mathrm{rd}=\$ 800\end{array}$ & $\begin{array}{l}\text { Additional } \\
\text { Peoples Choice } \\
\text { Award }\end{array}$ \\
\hline Small & Fall/Nov & 90 secs & $\begin{array}{l}\text { Round 1: 3- } \\
\text { 6pm; Round 2: } \\
\text { 9am-1pm }\end{array}$ & $\begin{array}{l}1 \mathrm{st}=\$ 1000 ; \\
2 \mathrm{nd}=\$ 500 ; 3 \mathrm{rd}=\$ 250\end{array}$ & $\begin{array}{l}\text { Workshops req; } \\
\text { Finals in real } \\
\text { elevator }\end{array}$ \\
\hline Small & Fall/Nov & $90 \mathrm{secs}$ & $\begin{array}{l}\text { Prelim } 2 \\
\text { hours; Finals } \\
\text { later that day; } \\
2 \text { hours }\end{array}$ & $\$ 1000$ total & $\begin{array}{l}\text { Pitch Comp for } \\
\text { Social Ideas; } \\
\text { Grad level } \\
\text { competition }\end{array}$ \\
\hline Large & Fall/Nov & 90 secs & $\begin{array}{l}\text { No prelim, top } \\
10 \text { decided by } \\
\text { application }\end{array}$ & $\begin{array}{l}\text { Winner gets } \\
\text { expenses paid to } \\
\text { CEO Conference }\end{array}$ & $\begin{array}{l}\text { Pitch Comp for } \\
\text { Arts }\end{array}$ \\
\hline
\end{tabular}




\begin{tabular}{|l|l|l|l|l|l|}
\hline Medium & Spring/March & $\begin{array}{l}1-2 \text { min } \\
\text { video }+5 \\
\text { min pitch }\end{array}$ & $\begin{array}{l}\text { Video then } \\
\text { verbal pitch }\end{array}$ & 1st=\$1500 & $\begin{array}{l}\text { Optional } \\
\text { workshop, other } \\
\text { pitch events incl. }\end{array}$ \\
\hline Large & Spring/March & 90 secs & $\begin{array}{l}\text { Top entries } \\
\text { from B-plan } \\
\text { comp only } \\
\text { competes }\end{array}$ & $\begin{array}{l}\text { Large prizemoney, } \\
\text { over } \$ 100 \mathrm{~K}\end{array}$ & $\begin{array}{l}\text { Number of other } \\
\text { comps; incentives } \\
\text { from multiple } \\
\text { sponsors }\end{array}$ \\
\hline Large & Fall/Nov & 90 secs & $\begin{array}{l}\text { One round, } \\
\text { approx. } 2 \\
\text { hours }\end{array}$ & $\begin{array}{l}1 \mathrm{st}=\$ 500+\text { trip to } \\
\text { CEO conf; } \\
2 \mathrm{nd}=\$ 300 ; 3 \mathrm{rd}=\$ 200\end{array}$ & $\begin{array}{l}\text { Addl. Social } \\
\text { Comp, open to } \\
\text { other schools, } \\
\text { several events }\end{array}$ \\
\hline Medium & Spring/Feb & $\begin{array}{l}30-60 \\
\mathrm{secs}\end{array}$ & $\begin{array}{l}\text { Written app; } \\
\text { consultations, } \\
\text { workshops }\end{array}$ & $\begin{array}{l}1 \mathrm{st}=\$ 2000 ; \\
2 \mathrm{nd}=\$ 1000,3 \mathrm{rd}= \\
\$ 500 \text { in scholarships }\end{array}$ & $\begin{array}{l}\text { Includes Com } \\
\text { Colleges; addl. } \\
\text { comp open for } \\
\text { prizemoney }\end{array}$ \\
\hline
\end{tabular}

As can be seen from these differing competitions, the amount of prizemoney, requirements, complexity and organization varies considerably. Obviously, the size and resources of each institution contributes to the variability, but some consistencies can be seen, notably in the time of the pitches. Each pitch session in these random examples is no longer than two minutes, which is a glaring difference with our own event (three minutes or at least $50 \%$ more time for the pitch). This may be an area where we can make an adjustment, although the length of pitches in the KR has not shown to be an issue in our case. Many events are simply held in one day, some requiring students to pitch twice, or some requiring a written application or business plan proposal prior, obviously helping with quality. While there is only one university listed here with video requirements, there are several others that ask for video entries, and some appear to use this as a filtering system to move on to a finals stage.

\section{PROS AND CONS OF PITCH COMPETITIONS}

\section{Pros}

Pros from the event have been numerous. For many students, whether entrepreneurship students or otherwise, they must practice creativity and innovation at some level in order to develop something new, and they must work to develop and justify a new venture around the idea. The business acumen required to develop a sound business model that would support the new product/service can be challenging for students and by simply going through the process adds to their business understanding. For entrepreneurship majors this aspect was already mentioned as very important for future success. Interestingly, an additional benefit realized by many students in either tier-level, was meeting business professionals who offered help for them to pursue their business ventures. This networking experience led not only to our students receiving help with their new product/service, but the additional benefit of increasing alumni interactions and relationships with the university.

Unlike some other university events that cater to specific schools or departments, this competition is applicable to all disciplines. For example, an art major certainly should consider monetizing their skills, or a mechanic at the technical college needs to think about how they will start, manage, and grow their business. In some cases team development is needed, and this is a skill critical for almost any professional, and a cross-pollination was created by many teams utilizing students from other disciplines as part of their team (computer science, biology, etc.). The counter to this position is the benefits of working alone and allowing students the autonomy to pursue their own individual ideas, and not having to rely on others. An obvious benefit is of course public speaking, the nervousness usually experienced by students speaking in front of strangers (and in this case experienced and older business professionals) rattles many students, particularly if they are new to business and pitching. On a more personal level faculty and students become 
closer (particularly if they have success), and this is an important factor at small and medium-sized schools and part of their value proposition.

There are many benefits for other stakeholders. The university experiences positive exposure within the local community and to their intended customers - students and their parents. The competition and its practical nature by including business professionals appeals to many, especially those who do not always agree with traditional academic education and methods of instruction. We also take considerable time to target local high schools and the business counselors that advise high school students. By inviting them to the Finals Round and acknowledging them that evening, we get to showcase the school, our program, faculty and the university at a very personal level. Alumni show a keen interest in being involved, either as a judge or audience member, that can lead to future financial support. Our own alumni foundation has become heavily involved in the recruiting judges, and the event's feel-good atmosphere becomes a positive selling point to generate alumni support. For the Business School we enjoy positive alumni relations and local press coverage, and in some cases nationally. An example being one winner receiving coverage from the Associated Press that was then picked up by over fifty national news outlets.

\section{Cons}

While there are many positives from hosting a pitch competition, we did experience some drawbacks. First, the amount of time and resources necessary from the school to establish, organize, promote, execute, and follow-up on the many moving parts exerts a great deal of time and resource pressure. For some faculty this would not be appealing and therefore may make it difficult to establish. It would normally require a faculty "champion" to move the project forward to make it sustainable. A faculty team may be the most practical and beneficial method. Support staff are important in this regard, from receiving entries to making lists to chasing missing students. Support staff allow faculty to do remain focused on the bigger picture and make strategic decisions towards success.

Second, there have been student complaints about the results. Many students (unsurprisingly) have argued their idea was better than another entry that may have made it through to the Finals Round. Anecdotally I would agree in some of these cases, but with the nature of the system this will undoubtedly occur, as judges have very different backgrounds and personalities, and ultimately decide, as they have confided, based on a "gut instinct" rather than the categories listed on the scoresheets. While this can be frustrating, it is difficult to be too harsh on those supporters who are volunteering their time. It should also be noted that these student complaints will no doubt occur whoever is judging, and it remains a strong argument for shifting the judging burden to external sources, as it moves the responsibility for this decisionmaking to others.

Finally, an interesting issue (but again unsurprising) has arisen with prizemoney. While the amount we have had to offer students is quite substantial and we acknowledge our good fortune, there have been issues with how it is shared amongst the winners when there is a team entry. As many of us know, students will often make claims of unequal workloads on projects, but when this level of prizemoney was on the line, the disputes in some cases became legal. For example, one team had a founder with an idea, she decided to bring in two others as part of a team, but when they won second place, the founder wanted more prizemoney as it was "her" idea. This was eventually resolved when they agreed to be heard by a faculty member who had a law degree and was experienced at reconciliation and both parties met and voiced their opinions and had to agree to the arbitrator's decision. This has become a surprise lesson for students, that they should agree beforehand who does what, and who gets what, and we suggest they put it in writing. Much like how a business partnership can go awry, it is best to have a written partnership agreement. As it turns out, students are learning more about how the "real world" works than just pitching an idea.

\section{IMPROVEMENTS FOR THE FUTURE}

As can be seen from the previous discussion, we have attempted to maintain a continuous improvement philosophy with the competition. However, the analysis can be improved with a formal interview process that attempts to discover how the event could be improved by interviewing three different stakeholder 
groups: students, judges and administrators. This sample represents a strong cross-section of the stakeholders involved with the event and can offer data on how the competition can be improved from these different perspectives (Creswell, 1997).

\section{Sample}

Interview participants were sourced from the student body and local area to include those that fit the three profiles of students, judge or administrators. Students were selected through a convenience sample and included those still in school taking classes; two had experienced success by making it through to the Finals Round, and two had not, providing different perspectives. Two judges were chosen based on similar convenience sample and personal networks. It was thought to be more effective to interview judges that have had multiple judging experiences with the event over the years, and one interviewee had judged twice and one three times previously. Finally, administrators included the person directly responsible for the event that provides the prizemoney. This individual is an obvious choice as they have been to every event since its inception and had a vested interest in seeing it improve. The second administrator worked as director of the local SBDC and teaches entrepreneurship classes at the university and has a requirement that students enter the event as part of assessment in the class. Once again, having a long-term involvement with the event and additionally being knowledgeable in entrepreneurship can add value to the findings.

An interview guide was created with specific questions for each participant and included three openended questions related to the competition and their perspectives. Most of the interviews were conducted face-to-face, and one was via email. The questions asked were:

1) From your perspective as a (student participant, judge, or administrator), what did you like about your experience with the Pitch Competition?

2) From your perspective as a (student participant, judge, or administrator), is there anything that you thought could be improved with the Pitch Competition?

3) Overall, from any viewpoint, how do you think the event could be improved?

\section{Results}

Students

Responses from students were generally positive, but they were not afraid to voice their opinion on negatives. Key findings that were positive was an overwhelming appreciation for the cash prizemoney. It did make a difference to push them to participate and try harder, and one student mentioned the "ROI is great" for the event. They also liked the necessity of being pushed to think through their business idea more thoroughly, because this was useful if they were to actually start their business, and this was particularly true for those two in the Finals Round. Finally, all were impressed with the Finals Round format, expanding on the earlier pitches, but also with its design to include the formality of dinner, the celebrity host as MC, large crowds, media coverage and the campus buzz it generated.

Key findings that were negative predominantly focused on judging. Firstly, interviewees discussed the inconsistencies from judges, some scoring very high, others very low in the same group. Second, they felt a lack of diversity with judges, more specifically that there were generational challenges as most were older. They felt this became a disadvantage when introducing a new product based around technology that is perhaps focused on younger target market, such as an app for example.

The last question dealt with anything that could be improved with the event, and this garnered some interesting feedback. Students were encouraged to create diverse teams and include students from other disciplines, but the question was how do they find these students? It is a question that should be addressed, perhaps by finding faculty champions in other disciplines to create networking events in the lead up to the competition. Several students would have appreciated more help in creating their pitch, particularly for the more detailed version required in the Finals Round. While we offered a seminar and some written guidance, they found it difficult figuring out details of what an effective pitch should be. One very interesting suggestion with regard to the judging conundrum, was to have the judging panel "specialize" in one of the category areas, meaning one judge scores only one category for each entry e.g. innovation. 
Judges

Judge responses to the positives of the event were centered on an appreciation of fostering entrepreneurial spirit in students. They were impressed with the range of ideas, their efforts and appreciated what the event was teaching them about business and public speaking. Negatives included not enough time to score appropriately due to the rapid pace of the event and some problems hearing students (no microphones are used in the Knockout Round). Once again, mention of a more standardized scoring system was discussed that might offer additional consistency between judges.

Some thought-provoking ideas were offered for the final question. One judge commented that while questions should be kept to a minimum several judges asked questions often. This could be considered unfair to other contestants, because if key information is left out of the pitch (e.g. price of a product) the judges can find out this information through questioning rather than deducting points for a poorer pitch. It was suggested that "better quality" judges should be used, however this would be difficult to define and execute. Other suggestions again included having younger judging panels and those more focused on technology as many of the student ideas centered around this area.

\section{Administrators}

The final set of stakeholders interviewed were administrators that were active behind the scenes of the event and maintained a history with the competition. Positives included reaching many of the objectives of the event, which is encouraging latent entrepreneurs, developing an entrepreneurial ecosystem for the campus and our community and promoting entrepreneurship. Negatives were few, one interviewee mentioned having a more detailed checklist for Finals Round participants, to make sure they cover specific areas such as marketing, finance, etc. Again, obtaining more consistency with judging was discussed. Some potentially useful ideas were to start the judge search much earlier in order to "vet" judges, making it more of an application process rather than just simply who can we get. The second suggestion was to train the judges prior to the event. This is interesting and would no doubt increase consistency, however hosting yet another event, another scheduling date and attempting to organize everyone may be too burdensome.

\section{IMPLEMENTATION GUIDE AND BEST PRACTICES}

The results from the preceding five-year analysis and the subsequent interviews has provided our event with ideas for continual improvement. Certainly, central to our success has been our sponsor, but seeing the improvement year-over-year has led to their overall satisfaction and continued support. The following is a summary of the implementation required and the steps to be taken that can lead to a "Best Practice" approach for a university pitch competition from the first five years.

TABLE 3

EVENTS, DATES AND DETAILS DURING FALL SEMESTER OF COMPETTION*

\begin{tabular}{|l|l|l|}
\hline Event & Date & Detail \\
\hline Select Dates & Previous Semester & $\begin{array}{l}\text { Mid- semester target, avoid other university events, two } \\
\text { weeks between KR \& FR }\end{array}$ \\
\hline Book Rooms & Previous Semester & Four rooms KR, banquet hall for FR \\
\hline Theme & Previous Semester & $\begin{array}{l}\text { Different theme each year e.g. Baseball (Pitch), Lego } \\
\text { (Build) }\end{array}$ \\
\hline $\begin{array}{l}\text { Assessment } \\
\text { Inclusion }\end{array}$ & Previous Semester & $\begin{array}{l}\text { Contact professors to see if event can be part of required } \\
\text { assessment }\end{array}$ \\
\hline Prizemoney & Previous Semester & $\begin{array}{l}\text { Confirm prizemoney with sponsors, how divided, new } \\
\text { ideas, etc. }\end{array}$ \\
\hline New Ideas & Summer & Discussion on implementing changes, ideas \\
\hline
\end{tabular}




\begin{tabular}{|c|c|c|}
\hline Posters / Flyers & Start of Semester & $\begin{array}{l}\text { Post throughout university, high-trafficked areas, notice } \\
\text { boards, etc. }\end{array}$ \\
\hline $\begin{array}{l}\text { Judges (KR \& } \\
\text { FR) }\end{array}$ & Early September & $\begin{array}{l}\text { Networks, SBDC, faculty, Dean/alumni, Alumni } \\
\text { Foundation }\end{array}$ \\
\hline Food Orders & Early September & Menu, finger food during KR, dinner for FR \\
\hline $\begin{array}{l}\text { FR Banquet } \\
\text { Details }\end{array}$ & Early September & $\begin{array}{l}\text { Tech. req., confirm MC, speakers, timetables, faculty \& } \\
\text { staff help, key invitations (President, Dean, important } \\
\text { alumni) }\end{array}$ \\
\hline $\begin{array}{l}\text { Emails to } \\
\text { Students }\end{array}$ & September \& Oct. & 2-3 emails to students (business/others), also tech school \\
\hline Announcements & September & University intranet sites, student login/landing page \\
\hline Classroom visits & September & $\begin{array}{l}\text { Entrepreneurship classes or other professors (first } 5 \text { mins } \\
\text { of class) }\end{array}$ \\
\hline Pitch Seminar & Week prior to KR & One-hour pitch practice seminar by Director of the SBDC \\
\hline Entries close & Week before KR & $\begin{array}{l}\text { Weekend/Monday for creation of four different pools of } \\
\text { students }\end{array}$ \\
\hline Entry Analysis & Friday before KR & $\begin{array}{l}\text { Chase incomplete entries, analyze numbers, adjust if } \\
\text { necessary }\end{array}$ \\
\hline Pools Created & Day before KR & $\begin{array}{l}\text { Four pools created, lists developed that can be displayed } \\
\text { next day }\end{array}$ \\
\hline \multirow[t]{2}{*}{$\begin{array}{l}\text { Knockout } \\
\text { Round (KR) }\end{array}$} & Tuesday afternoon & $\begin{array}{l}\text { From 1-3pm, four pools, approx. } 12-13 \text { entries per room. } \\
\text { Top entry from each room advance to FR (plus the closest } \\
\text { second entry) for a total of five. Three judges/room, 3- } \\
\text { minute pitches, } 5 \text { min./per pitch. }\end{array}$ \\
\hline & Tuesday pm & $\begin{array}{l}2: 45 \mathrm{pm} \text { announcement of winners, further information on } \\
\text { FR. }\end{array}$ \\
\hline Invitations & $\begin{array}{l}\text { Immediately } \\
\text { following KR }\end{array}$ & $\begin{array}{l}\text { Invitation only to FR - alumni, school benefactors, faculty, } \\
\text { student family members, local high school business } \\
\text { counselors \& students, President, Dean, sponsor attendees, } \\
\text { etc. (free entry with invitation) }\end{array}$ \\
\hline $\begin{array}{l}\text { Student } \\
\text { Instructions }\end{array}$ & Week Following KR & $\begin{array}{l}\text { Specific FR instructions to students, length, PPT, tech } \\
\text { requirements, etc. }\end{array}$ \\
\hline $\begin{array}{l}\text { Announcements } \\
\text { /PR }\end{array}$ & Local news outlets & Invite TV stations, newspaper, student paper \\
\hline $\begin{array}{l}\text { Finals Round } \\
\text { (FR) }\end{array}$ & $\begin{array}{l}\text { Two weeks later } \\
\text { (evening) }\end{array}$ & $\begin{array}{l}\text { Guests can arrive between } 615-645 \mathrm{pm} \text {, take seats by } 7 \mathrm{pm} \\
\text { for appetizers, short announcements, dinner served. }\end{array}$ \\
\hline Procedure & & $\begin{array}{l}\text { Pitches begin at } 730 \mathrm{pm} \text { and finish by } 830 \mathrm{pm} \text {. Scores } \\
\text { tallied, certified. Announcements made at } 845 \mathrm{pm} \text {, awards, } \\
\text { photos, etc. Wrap at } 9 \mathrm{pm} \text {. }\end{array}$ \\
\hline Follow up & Next day/week & $\begin{array}{l}\text { Email announcements of winners to all participants, judge } \\
\text { thank and sponsor thank you messages, press releases to } \\
\text { news outlets, student payment information, feedback \& } \\
\text { analysis }\end{array}$ \\
\hline $\begin{array}{l}\text { National } \\
\text { Conference }\end{array}$ & Weeks after event & $\begin{array}{l}\text { Follow up with student entry, coaching, attend conference, } \\
\text { reimburse expenses, etc. }\end{array}$ \\
\hline $\begin{array}{l}\text { Announcements } \\
\text { /PR }\end{array}$ & $\begin{array}{l}\text { Local news / } \\
\text { University outlets }\end{array}$ & $\begin{array}{l}\text { Information shared with news outlets, university paper, } \\
\text { sponsors, alumni, etc. }\end{array}$ \\
\hline
\end{tabular}

*An addendum to this guide is provided in the Appendix (C) 


\section{RECENT ADDITIONS AND CHANGES}

It should be noted that at the time of writing this article, some of the changes discovered during the analyses were implemented with great success. Notably addressing the feedback on judging and improving the quality of the pitches. Another layer of judging was included that allowed for a fairer and more consistent scoring of entries called the "Semi Final Round." The top three entries from each of the four pools were included in the Semi Final stage, where participants had to pitch a second time to a different panel of five judges immediately following the Knockout Round, and this had several positive effects. First, it allowed more entries through to the next tier, reducing the problem of some higher quality not making it through. Second, the entire group were then scored by the same judging panel, which improved consistency. Third, the increased number of judges from three to five reduced variability in the panel scores. Each losing Semi Finalist received a cash prize of $\$ 100$ on a VISA gift card.

Another improvement was the addition of mentors that were assigned to each of the five Finals Round participants. The mentors were required to guide the students through the process and give them experienced and professional feedback to improve their final presentations. Each student/team was asked to include basic foundational requirements in the final pitch that included specific areas such as marketing, competitor analysis, management, and sound financials. The mentors were assigned to make sure these areas were understood, researched adequately and presented well. Two meetings with the student/team were required at a minimum and one meeting with the mentor must include hearing the pitch presentation. This had the effect of much more polished, complete, and professional presentations during the Finals Round. An addendum to the Implementation Guide that includes the Semi Final Round and mentors is included in the Appendix (C).

\section{CONCLUSION}

There is currently little research being conducted in this area, although papers from Faff and Spinuzzi are some notable exceptions. The growing list of academics teaching entrepreneurship or creating new entrepreneurship classes and programs will benefit from this research (Morris, Kuratko \& Pryor, 2014). This analysis will also benefit future researchers as it not only creates a blueprint for best practices with pitch competitions but adds to the discourse in the field. University-level administrators understand the advantages of these events as institutions fight for enrollment. Additionally, as many students across the United States continue to look for justification in the value of a college education, and this applied, valueadded approach contributes to the marketability of any institution, particularly as it is an experience that cannot be replicated online.

Alumni appreciate the competitions, they value the effort of students and importantly like to be involved in the process. While traditional methods of alumni interactivity have generally revolved around classroom lectures as guest speakers, pitch competitions allow for alumni to become closer to the learning process with less effort, they can offer valuable advice as a judge and enjoy utilizing their experiences and expertise. Furthermore, these interactions provide networking opportunities and ultimately help students whether they pursue a new venture or not. This prized moment of connection between alumni and students is often a critical juncture in fund raising and is noted in the literature, and has been a strength of entrepreneurship programs in general (Morris, Kuratko \& Cornwall, 2013).

Student-faculty relationships become stronger through intimate conversations with a student or groups of students as faculty help mentor projects through the event. It is often of less importance whether or not the student(s) actually pursue the business opportunity, but the perceived attention and enthusiasm from faculty for a student idea is a worthy goal in the mind of students, their parents and their peers. Relationships with economic development (ED) agencies and other business community groups can be nurtured and grown as the university contributes to their vision and goals of producing entrepreneurs, who in turn create businesses and jobs for local communities (Wright, Siegel \& Mustar, 2017). Universities benefit from financial support as they nurture and grow this potential relationship with the community, and 
ED organizations provide networking opportunities with community leaders for students while receiving positive publicity.

This research advances the literature in the entrepreneurship education area, and adds insight into best practices involved with introducing and refining a pitch competition for institutions of higher education or other organizations. Research suggests that entrepreneurs' communication skills and personal attributes during the pitch influences investor decision making and is thus a critical skill and worthy of development (Pogue \& Spinuzzi, 2016). Therefore, the development of these competitions, inside the relatively safe confines of the university, allows students to develop a very important proficiency. This makes the introduction of a successful pitch competition a valuable complementary program for any entrepreneurship curriculum.

\section{REFERENCES}

Balachandra, L., \& Fischer, K. (2016). Words Matter: Men, Women and the Power of the Spoken Word in Entrepreneurial Pitching. Frontiers of Entrepreneurship Research, 36(2), 1.

Clark, C. (2008). The impact of entrepreneurs' oral 'pitch' presentation skills on business angels' initial screening investment decisions. Venture Capital, 10(3), 257-279.

Clingingsmith, D., \& Shane, S. (2018). Training aspiring entrepreneurs to pitch experienced investors: Evidence from a field experiment in the United States. Management Science, 64(11), 5164-5179.

Cremades, A. (2016). The art of startup fundraising: Pitching investors, negotiating the deal, and everything else entrepreneurs need to know. John Wiley \& Sons.

Creswell, J.W. (1997). Qualitative Inquiry and Research Design: Choosing Among Five Traditions. Thousand Oaks, CA: Sage Publications.

Green, W.S., \& Brooks, R. (2008). Entrepreneurship in American higher education. Kauffman Thoughtbook, 2009, 111-117.

Katz, J.A., \& Green, R.P. (2018). Entrepreneurial small business. McGraw-Hill Education.

Maxwell, A.L., \& Lévesque, M. (2014). Trustworthiness: A critical ingredient for entrepreneurs seeking investors. Entrepreneurship Theory and Practice, 38(5), 1057-1080.

McGowen, W. (2015). The Pitch Perfect. New York: Harper Collins.

Morris, M.H., Kuratko, D.F., \& Cornwall, J.R. (2013). Entrepreneurship programs and the modern university. Edward Elgar Publishing.

Morris, N.M., Kuratko, D.F., \& Pryor, C.G. (2014). Building blocks for the development of universitywide entrepreneurship. Entrepreneurship Research Journal, 4(1), 45-68.

Pogue, G., \& Spinuzzi, C. (2016, October). Pitching: Strategies for structuring, engaging, and winning over audiences. In Professional Communication Conference (IPCC), 2016 IEEE International (pp. 1-2). IEEE.

Wright, M., Siegel, D.S., \& Mustar, P. (2017). An emerging ecosystem for student start-ups. The Journal of Technology Transfer, 42(4), 909-922.

\section{APPENDICES}

Appendix A: Knockout Round (KR) Judging Criteria

\begin{tabular}{|l|l|}
\hline KNOCKOUT ROUND (KR) & \\
\hline Judging Criteria & Score \\
\hline 1) Innovation & $0-25$ \\
\hline Is this a new idea or how is it different? & \\
\hline 2) Business Model & $0-25$ \\
\hline How will the business operate and knowledge of the industry/market? & \\
\hline
\end{tabular}

160 Journal of Higher Education Theory and Practice Vol. 21(9) 2021 


\begin{tabular}{|l|l|}
\hline 3) Feasibility & $0-25$ \\
\hline Is it realistic to implement? & \\
\hline 4) Presentation & $0-25$ \\
\hline Was the delivery polished and impressive? & \\
\hline \hline Total / 100 & \\
\hline
\end{tabular}

\section{Appendix B: Finals Round (FR) Judging Criteria}

\begin{tabular}{|l|l|}
\hline FINALS ROUND (FR) & \\
\hline Judging Criteria & Score \\
\hline 1) Value Proposition / Differentiation / Innovation & $0-20$ \\
\hline $\begin{array}{l}\text { Does the product or service provide something novel/unique/special that gives it a } \\
\text { competitive advantage? }\end{array}$ & $0-20$ \\
\hline 2) Business Model Understanding & \\
\hline $\begin{array}{l}\text { Did the team/person demonstrate knowledge of the industry/market and how the business } \\
\text { will operate? }\end{array}$ & $0-20$ \\
\hline 3) Feasibility & \\
\hline Is the proposed business venture realistic to implement? & $0-20$ \\
\hline 4) Future Potential / Scalability & $0-20$ \\
\hline Does the opportunity represent significant growth potential? & \\
\hline 5) Presentation & \\
\hline $\begin{array}{l}\text { The team/person presented their venture idea in a logical, persuasive manner and answered } \\
\text { questions well. }\end{array}$ & \\
\hline \hline Total / 100 & \\
\hline
\end{tabular}

Appendix C: Addendum and Recent Additions to the Implementation and Best Practices Timetable

\begin{tabular}{|l|l|l|}
\hline Event & Date & Detail \\
\hline Mentor Selection & Early September & $\begin{array}{l}\text { Based on background, WOM referrals, } \\
\text { one mentor per student/team }\end{array}$ \\
\hline Mentor Requirements & $\begin{array}{l}\text { Sufficient time to meet, be present at } \\
\text { KR and FR, guidelines given }\end{array}$ \\
\hline Semi Final Round & Immediately following KR & $\begin{array}{l}\text { Top three entries from four pools must } \\
\text { pitch a second time to a panel of five } \\
\text { judges, same rules and judging criteria }\end{array}$ \\
\hline Announcement of SF Winners & Immediately following SF & Five judges tally scores \\
\hline SF Prizes Awarded & Immediately following SF & \$100/per SF, VISA gift card (7) \\
\hline Mentor Introductions & $\begin{array}{l}\text { After FR winners } \\
\text { announced }\end{array}$ & Be present at SF stage to see pitches \\
\hline Mentor/Student Meetings & Twice minimum & $\begin{array}{l}\text { Must meet twice, once face-to-face. } \\
\text { One meeting must include a practice } \\
\text { presentation of the entire pitch using } \\
\text { technology e.g. PPT }\end{array}$ \\
\hline
\end{tabular}

